\title{
Authors Cited in Notes
}

Adams, Romanzo, 324, 326, 327, 343, 345

Alexander, Arthur C, 322

Allen, E. H., 323

Baker, Hugh D. R., 352

Ball, James Dyer, 345, 348, 362

Barth, G., 346, 352

Bennett C. C, 324, 340, 349

Bonk, William J., 348

Chang, D. C., 361

Char, Tin-Yuke, 323, 326, 327, 329, 333, 336, 337, 343, 346, 348, 352, 356, 358, 359, 361, 364

Char, Wai-Jane, 322, 323, 329, 346, 356, 364

Chock Lun, 346, 356, 364

Chun, Chee Kwon, 329, 342

Chung Kun Ai (C. K. Ai), 324, 329, 330, 332, 333, 334, 340, 342, 343, 345, 352, 356, 359, 361, 365

Comber, Leon, 348

Couling, S., 346

Coutler, John W., 329, 330, 342

Crissman, Lawrence W., 358

Cruzan, J. A., 324

Culin, Stewart, 340

Damon, Frank W., 327, 343, 348

Diell, John, 322

Fallers, L. A., 346

Fei, Hsiao-Tung, 336
Freedman, Maurice, 336

Gilman, Gorham D., 342

Girvin, James W., 330

Glick, Clarence E., 323, 332, 340, 362

Gong, Ted T. K., 348

Goo, Paul Kimm Chow, 337

Goto, Y. Baron, 330, 332

Greer, Richard A., 353

Hill, Harold C, 358

Hill, S. S., 324

Hoy, William, 358

Huff, Lehn, 345

Hull, George Charles, 353

Ip, David Fu-Keung, 333

Iwai, Charles K., 329, 330

Iwamoto, Lana, 353

Jones, Idwall, 332

Kai, Dan Kane-za, 327

Kai, Peggy, 322, 364

Koga, Loraine, 333

Kuykendall, Ralph S., 329, 348, 349, 351, 352

Lai, Bessie C, 364

Lai, Kum Pui, 334, 337, 345, 355, 361, 365

Lee, Aileen O. L., 358

Lee, Bung Chong, 333, 336, 340 
Lee, Robert M. [W.], 330, 332, 333, 334, 337, 356

Lee, Rose Hum, 348

Leong, Ah Jook Ku, 339

Li Ling Ai, 336, 342, 343, 353, 359, 362, 364

Liang, Phoebe, 359

Lim-Chong, Lily, 342, 362

Lind, Andrew W., 327, 332

Lo, Mei-Li Lee, 365

Lorden, Doris M., 345

Luke, William K., 358, 359

Lund, A. S. T., 329, 330

Mark, Diane Mei Lin, 330, 348, 359

McDowell, H. B., 342

Meares, John, 322

Morgan, W. P., 348

Murata, K., 329, 330

Nee, Brett de Bary, 351

Nee, Victor G., 351

Palmer, A. W., 340

Pickering, W. A., 346, 348

Pope, Willis T., 332
Rebel, A., 329

Restarick, H. B., 359

Reynolds, Stephen, 346

Siu, Paul C. F., 345

Soong, Irma Tam, 348, 358

Speer, William, 355

Taylor, Wray, 327

Thom, Wah Chan, 334

Tong, Ah Huna, 343

Torbert, L. L., 322

Tse, Winnie, 333

Vancouver, George, 322

Wirth, Louis, 332

Wong, Elizabeth, 326, 364

Wong, K. Chimin, 343

Wong, Sau Chun, 343

Wu, Ching-chao, 340, 342

Wu, Lien-Teh, 343

Yang, C. K., 336

Young, Lum Pui, 346 
Map 1. Kwangtung Province

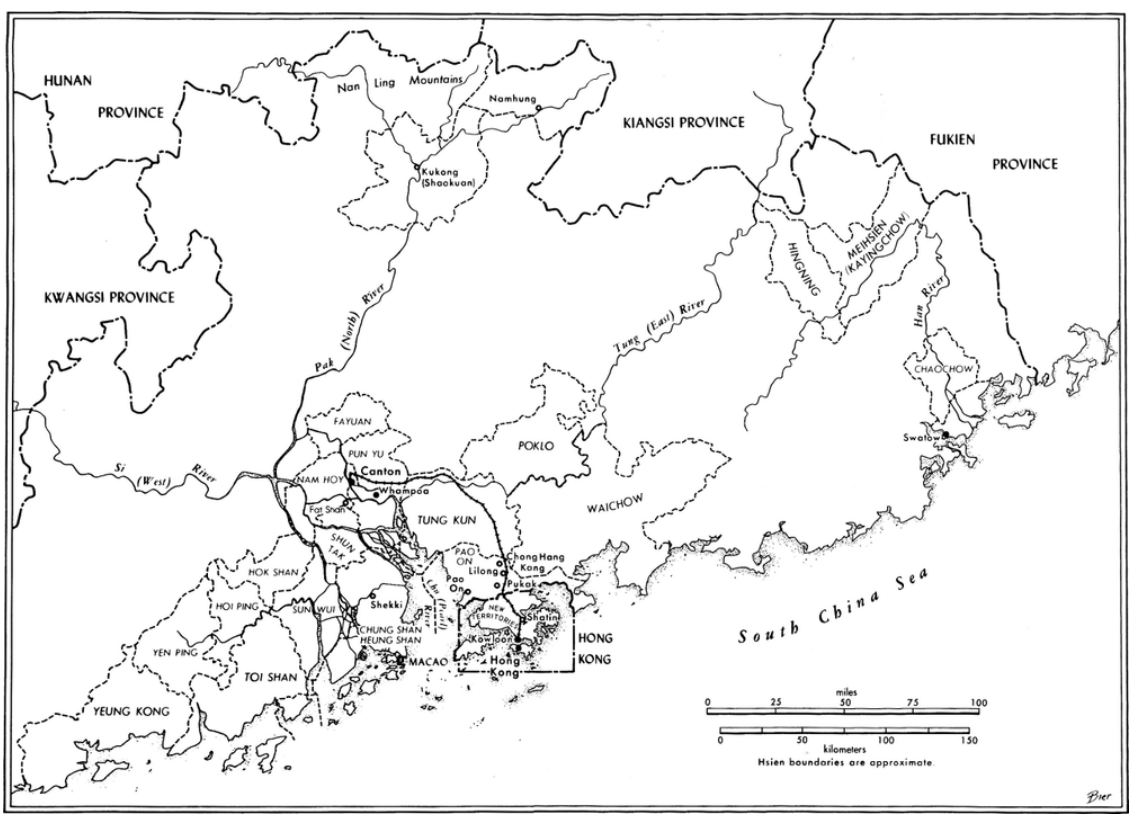

Source: Tin-Yuke Char, The Sandalwood Mountains (Honolulu: University Press of Hawaii, 197 pp. 18-19. 